
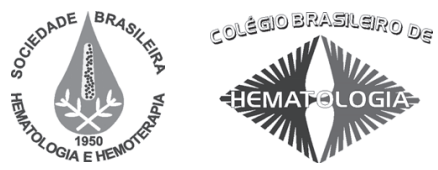

Editoriais e Comentários / Editorials and Comments

\section{Tácito Portella Barbalho Tácito Portella Barbalho}

\section{Divaldo A. Sampaio}

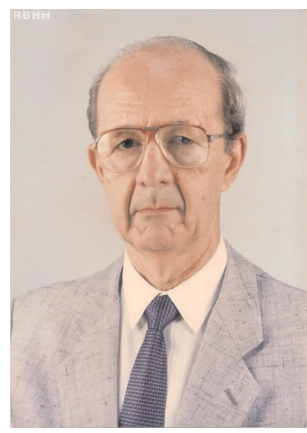

A Hematologia nacional perdeu um de seus maiores nomes com a morte, no dia 05 de julho de 2009, do médico Tácito Portella Barbalho, aos 81 anos. Formado pela Universidade Federal de Pernambuco, em 1960, logo ingressou no Serviço de Clínica Médica do Prof. Amaury Coutinho, do Hospital das Clínicas da UFPE, como residente, aí permanecendo até 1963 , indo realizar especialização no Serviço de Hematologia do Prof. Marshal, em Paris. Lá se especializou, realizou o mestrado e obteve o título de Assistente Estrangeiro. De volta ao Brasil e com a chegada ao Recife dos equipamentos doados pelo Governo francês, instala e passa a chefiar a Enfermaria de Hematologia, pondo em prática, no Hospital Universitário Oswaldo Cruz, seus conhecimentos adquiridos em Paris. Assume a direção desse hospital, desenvolvendo atividade docente de Hematologia na Faculdade de Ciências Médicas da Universidade de Pernambuco, onde foi, também, preceptor da Residência Médica. Em 1968, retorna à França e realiza o doutorado em Toulouse, obtendo o grau de Doutor em Ciências, sob a orientação do Professor Ouayon, desenvolvendo tese sob o título: "Étude de l'activité des anticorps produits chez l'homme à la suíte d'immunisation par les antigènes leucocytaires et plaquetaires". Ao retornar, reassume suas funções no Instituto de Hematologia e Transfusão Sanguínea da Faculdade de Ciências Médicas, permanecendo até 1977, quando inaugurou, juntamente com o Dr. Luiz Gonzaga dos Santos, o Centro de Hematologia e Hemoterapia de Pernambuco - Hemope, do qual passou a ser o vice-presidente até 1983. No Hemope, foi diretor do Serviço de Hematologia e se ocupou em organizar o Laboratório de Histocompatibilidade, primeiro do Norte e Nordeste do Brasil, inaugurado em 1979. Foi, por assim dizer, o primeiro passo para a criação do Centro de Transplante de Medula Óssea da Fundação Hemope, que, em 2002, passou a se chamar Centro de Transplante de Medula Óssea Tácito Portella Barbalho, em homenagem ao seu idealizador. Em 1987 assumiu a presidência do Hemope e lançou o $1^{\circ}$ Plano Diretor de Desenvolvimento - PDD, que vigorou até 1991. Nessa ocasião, convidado pelo ministro da Saúde, Dr. Luiz Carlos Borges da Silveira, assumiu a Divisão Nacional de Sangue e Hemoderivados - Dinashe, quando implantou o Planashe, Plano
Nacional do Sangue e Hemoderivados, permanecendo como diretor até 1989. Nesse mesmo ano, seguiu para a República Federal da Alemanha, a fim de realizar o pós-doutorado na Universidade de Munique. Publicou vários trabalhos científicos, participou de congressos, simpósios e workshops da Sociedade Internacional de Histocompatibilidade, foi diretor do Banco de Reagentes da Associação Brasileira de Histocompatibilidade, exercendo suas atividades até o ano de 1996. É considerado um dos precursores da Hematologia no Norte e Nordeste do País, tendo desempenhando papel destacado na difusão dos conhecimentos e do ensino da especialidade, formando numerosos residentes e especialistas. Em Tácito Barbalho, juntamente com outras importantes qualidades, havia um tesouro inesgotável de sabedoria, de boa-fé, de amizade constante e inviolável, de uma inteligência rara, cultivada com bondade paternal. Homem de caráter, era incapaz de ceder às vãs atitudes dos desonestos, pois sustentou durante toda sua vida, a dignidade de suas glórias, de sua pureza, de sua bondade.

Avaliação: O tema abordado foi sugerido e avaliado pelo editor.

Recebido: 24/07/2009

Aceito: 24/07/2009

Professor Adjunto da Universidade de Pernambuco. Presidente da Fundação Hemope.

Correspondência: Divaldo de Almeida Sampaio Rua Conselheiro Portella, 130 A, Apto 1301 - Espinheiro 52020-030 - Recife-PE - Brasil

E-mail:dasampaio@hotmail.com 